Jurnal Kebijakan Pembangunan Daerah, Vol.5, No.2, Desember 2021, Hal. 123 - 137

p-ISSN: 2597-4971, e-ISSN: 2685-0079

\title{
PELAKSANAAN PROGRAM KAMPUNG KELUARGA BERENCANA DI KELURAHAN NYAPAH KECAMATAN WALANTAKA KOTA SERANG
}

\section{THE IMPLEMENTATION OF THE FAMILY PLANNING VILLAGE PROGRAM IN THE VILLAGE OF NYAPAH, AT WALANTAKA DISTRICT OF SERANG CITY}

(disubmit 15 Oktober 2021, direvisi 25 November 2021, diterima 29 November 2021)

Siti Rohayati, Leo Agustino, dan Rina Yulianti

Magister Administrasi Publik Pascasarjana Universitas Sultan Ageng Tirtayasa

Jl. Raya Jakarta Km. 4 Pakupatan Serang

Email : SitiRohayati0201@gmail.com

\begin{abstract}
ABSTRAK
Pelaksaan program Kampung KB di Kelurahan Nyapah, terdapat beberapa masalah seperti: kurangnya kesadaran masyarakat yang termasuk kedalam Pasangan Usia Subur (PUS) yang belum mengikuti sebagai peserta Keluarga Berencana (KB), kurangnya fasilitas kesehatan yang ada di Kampung KB Kelurahan Nyapah dan belum maksimalnya partisipasi masyarakat dalam pembinaan ketahanan keluarga di program Kampung KB Kelurahan Nyapah. Penelitian ini bertujuan untuk mengetahui implementasi program, faktor-faktor yang menghambatnya, dan upaya-upaya yang dapat dilakukan dalam memperbaiki pelaksanaan program Kampung KB) di Kelurahan Nyapah Kecamatan Walantaka Kota Serang. Teori yang digunakan teori implementasi Model Van Metter dan Van Horn. Metode penelitian yang digunakan adalah kualitatif deskriptif. Hasil penelitian menunjukkan bahwa pelaksanaan Program Kampung KB dikelurahan Nyapah belum berjalan dengan maksimal hal ini dilihat dari pelaksanaan program ini yang tidak berjalan lagi serta banyak kekurangan dari berbagai indikator diantaranya sumber daya finansial; kurangnya kesadaran masyarakat yang termasuk kedalam Pasangan Usia Subur (PUS) yang belum mengikuti sebagai peserta KB; kurangnya partisipasi dan kesadaran Masyarakat dalam pembinaan ketahanan keluarga, dan upaya untuk memperbaiki pelaksaan program kampung KB dengan melakukan evaluasi program; evaluasi ketersediaan sumber daya yang mendukung dan melakukan koordinasi secara vertikal dan horizontal.
\end{abstract}

Kata Kunci: Pertumbuhan penduduk, pelaksanaan program, dan Kampung KB

\section{ABSTRACT}

In the implementation of the Kampung KB program in Nyapah Village, there are several problems such as: lack of awareness of the people who are included in the Childbearing Age Couple who have not participated as Family Planning (KB) participants, lack of health facilities in the Kampung KB, Nyapah Village and not maximal participation community in fostering family resilience in the Kampung $K B e$ program, Nyapah Village. This study aims to determine the implementation of the program, the factors that hinder it, and the efforts that can be made to improve the implementation of the Kampung KB program in Nyapah Village, Walantaka District, Serang City. The theory used is the implementation theory of the Van Metter and Van Horn Models. The research method used is descriptive qualitative. The results of the study indicate that the implementation of the Kampung KB Program in the Nyapah village has not run optimally, this can be seen from the implementation of this program which is no longer running and there are many shortcomings from various indicators including financial resources; lack of awareness of the people who are included in the fertile age couple who have not participated as family planning participants; lack of community participation and awareness in fostering family resilience, and efforts to improve the implementation of the Kampung KB program by conducting program evaluations; evaluate the availability of supporting resources and coordinate vertically and horizontally.

Keywords: population growth, Kampung KB, implementation program 


\section{PENDAHULUAN}

Angka kelahiran mempengaruhi jumlah penduduk karena dengan adanya kelahiran, jumlah penduduk pun bertambah dan akan terus meningkat. Di Indonesia dari tahun ke tahun angka kelahiran serta pertumbuhan penduduk terus terjadi, berdasarkan data yang dipublikasikan oleh Badan Pusat Statistik Nomor 07/01/Th. XXIV.21 Januari 2021 bahwa jumlah penduduk Indonesia pada September tahun 2020 sebanyak 270,20 juta jiwa, semenjak Indonesia melakukan sensus penduduk setiap sepuluh tahun sekali, selalu menunjukkan peningkatan pada setiap sensus penduduk yang dilakukan pemerintah. Berdasarkan berita resmi statistik tersebut hasil sensus penduduk mengalami pertambahan penduduk 32,56 Juta Jiwa penduduk dibandingkan dengan sensus penduduk pada tahun 2010 (BPS-RI, 2021).

Pertambahan penduduk yang terjadi pada sensus penduduk yang dilakukan ditahun 2020 sebesar 32,56 Juta Jiwa, jika diambil rata-rata pertambahan penduduk setiap tahunnya sebesar 3,26 juta jiwa setiap tahunnya. Sementara itu dalam kurun waktu sepuluh tahun terakhir dari tahun 2010-2020 laju pertumbuhan penduduk Indonesia sebesar 1,25\% pertahun (BPSRI, 2020) dan ini bisa menjadi permasalahan akut yang kalau tidak dikendalikan maka Indonesia akan mengalami ledakan penduduk. Untuk mengatasi permasalah tersebut pemerintah telah merancang program Keluarga Berencana. (Pada bulan Novembar 1968 pemerintah mendirikan Lembaga Keluarga Berencana Nasional (LKBN), yang dalam menjalankan tugasnya diawasi dan dibimbing oleh Menteri Negara Kesejahteraan Rakyat. Pada tahun 1969 program KB masuk dalam Pelita I dan merupakan bagian dari program pembangunan nasional. Kemudian pada tahun 1970 didirikan BKKBN (Badan Kependudukan dan Keluarga Barencana Nasional), menggantikan LKBN (Singarimbun, 1996). Program Keluarga Berencana menurut Undang-undang nomor 10 tahun 1992 tentang perkembangan kependudukan dan pembangunan keluarga sejahtera mengatakan bahwa Keluarga Berencana adalah upaya peningkatan kepedulian dan peran serta masyarakat melalui pendewasaan usia perkawinan, pengaturan kelahiran, pembinaan ketahanan keluarga serta peningkaan kesejahteraan keluarga untuk mewujudkan keluarga kecil, bahagia dan sejahtera. Undang-undang nomor 10 tahun 1992 kemudian diperbarui dengan adanya Undang-undang nomor 52 tahun 2009 tentang perkembangan kependudukan dan pembangunan keluarga menyebutkan 
Jurnal Kebijakan Pembangunan Daerah, Vol.5, No.2, Desember 2021, Hal. 123 - 137

p-ISSN: 2597-4971, e-ISSN: 2685-0079

bahwa, Keluarga Berencana adalah upaya mengatur kelahiran anak, jarak, usia ideal melahirkan, mengatur kehamilan, melalui promosi, perlindungan, dan bantuan sesuai dengan hak reproduksi untuk mewujudkan keluarga yang berkualitas.

Kota Serang termasuk kota yang mempunyai persoalan terhadap laju pertumbuhan penduduk yang cukup tinggi dari tahun ke tahun seperti yang ditunjukkan Tabel 1 berikut.

Tabel 1 Penduduk Kota Serang 2017 -

2019

\begin{tabular}{|c|l|r|r|r|}
\hline \multirow{2}{*}{ No } & \multicolumn{4}{|c|}{ Penduduk Kota Serang (Jiwa) } \\
\cline { 2 - 5 } & Kecamatan & \multicolumn{1}{|c|}{2019} & \multicolumn{1}{c|}{2018} & \multicolumn{1}{c|}{2017} \\
\hline 1. & Curug & 51.475 & 50.885 & 51.204 \\
\hline 2. & Walantaka & 96.678 & 92.253 & 94.487 \\
\hline 3. & $\begin{array}{l}\text { Cipocok } \\
\text { Jaya }\end{array}$ & 118.587 & 109.793 & 114.162 \\
\hline 4. & Serang & 224.546 & 226.717 & 230.196 \\
\hline 5. & Taktakan & 94.074 & 90.960 & 92.550 \\
\hline 6. & Kasemen & 97.593 & 95.992 & 96.838 \\
\hline \multicolumn{2}{|c|}{ Kota Serang } & 688.603 & 677.804 & 666.600 \\
\hline
\end{tabular}

Sumber: BPS Kota Serang, (2020) diolah

Tingginya angka kelahiran menjadi faktor utama terjadinya pertambahan penduduk. Permasalahan inilah yang menjadi asal mula dikeluarkannya Program Kampung Keluarga Berencana KB untuk wilayah Kota Serang. Ini sesuai dengan Amanat Presiden RI Joko Widodo Pada tanggal 14 januari 2016 kepada BKKBN agar dapat menyusun suatu kegiatan/ program yang dapat memperkuat upaya pencapaian target/sasaran Pembangunan Bidang Pengendalian Penduduk dan
Keluarga Berencana 2015-2019

(Kemenkominfo, 2016). Dalam rangka menindaklanjuti pencanangan Kampung KB oleh Bapak Presiden RI dibuatlah Surat Edaran Menteri Dalam Negeri Republik Indonesia Nomor: 440/70/SJ. Lalu setelah mendapat surat edaran, Walikota Serang mengeluarkan Surat Keputusan Walikota Serang Nomor: 476/Kep.223-Huk/2017 tentang Penunjukan Dan Penetapan Lokasi Kelurahan Binaan Untuk Pelaksanaan Program Terpadu Kependudukan Dan Kampung Keluarga Berencana Kota Serang.

Dinas Pemberdayaan Perempuan, Perlindungan Anak, dan Keluarga Berencana (DP3AKB) Kota Serang menjadi penanggungjawab utama masalah KB di Kota Serang. Tugas Pokok dan Fungsi Berdasarkan pasal 2 peraturan walikota nomor 14 tahun 2017. Dinas Pemberdayaan Perempuan, Perlindungan Anak dan Keluarga Berencana mempunyai tugas pokok melaksanakan urusan wajib non pelayanan dasar di bidang pemberdayaan perempuan, perlindungan anak dan pelayanan program keluarga berencana. DP3AKB dalam melaksanakan tugas menyelenggarakan fungsi dan kewenangan:

a. Perumusan kebijakan teknis pelaksanaan urusan dibidang pemberdayaan perempuan dan masyarakat, perlindungan perempuan dan anak, pengendalian penduduk, 
advokasi penggerakan dan informasi serta keluarga berencana, ketahanan dan kesejahteraan keluarga;

b. Pelaksanaan kebijakan sesuai dengan bidang pemberdayaan perempuan dan masyarakat, perlindungan perempuan dan anak, pengendalian penduduk, advokasi penggerakan dan informasiserta keluarga berencana, ketahanan dan kesejahteraan keluarga;

c. Pelaksanaan evaluasi dan pelaporan dibindang pemberdayaan perempuan dan masyarakat, perlindungan perempuan dan anak, pengendalian penduduk, advokasi penggerakan dan informasi serta keluarga berencana, ketahanan dan kesejahteraan keluarga;

d. Pelaksanaan administrasi dinas seuai dengan bidang pemberdayaan perempuan dan masyarakat, perlindungan perempuan dan anak, pengendalian penduduk, advokasi penggerakan dan informasi serta keluarga berencana. Ketahanan dan kesejahteraan keluarga;

e. Pengelolaan UPT; dan Pelaksanaan tugas lain yang diberikan walikota sesuai dengan lingkup tugas dan fungsinya. (Peraturan Walikota Serang Nomor 14 tahun 2017).

\section{Pelaksanaan Program Kampung KB}

di kelurahan Nyapah Kota Serang ini sudah berjalan baik namun belum optimal dikarenakan masih adanya faktor-faktor yang menghambat keberhasilan pelaksanaan program keluarga berencana di kelurahan ini Adapun permasalahanpermasalahan yang terjadi sebagai berikut:

Pertama, kurangnya kesadaran masyarakat yang termasuk kedalam Pasangan Usia Subur (PUS) yang belum seluruhnya mengikuti sebagai peserta Keluarga Berencana KB. Kesadaran menjadi faktor penting dalam mendorong keberhasilan sebuah program sehingga program tersebut dapat berjalan sesuai dengan tujuan yang telah ditetapkan dalam program Kampung KB. Berdasarkan data Kelurahan Nyapah dalam Laporan Bulanan Pengendalian Lapangan Tingkat Kelurahan Sistem Informasi Kependudukan dan Keluarga bulan Desember 2020 diketahui bahwa jumlah Pasangan Usia Subur (PUS) sebanyak 942, namun Pasangan Usia Subur yang mengikuti program Keluarga Berencana KB hanya sebanyak 801, ini artinya ada sebanyak 141 Pasangan Usia Subur yang bukan peserta KB.

Kedua, kurangnya fasilitas kesehatan yang ada di Kampung KB Kelurahan Nyapah Kecamatan Walantaka. Keberadaan fasilitas kesehatan akan mendukung jalanya program sehingga pelaksanaan program akan optimal, berdasarkan data yang ada dalam Kecamatan Walantaka dalam Angka tahun 2020 diketahui jumlah fasilitas kesehatan berupa Puskesmas pembantu (Pustu) hanya ada 1 Puskesmas pembantu dengan jumlah penduduk sebanyak 4.389 jiwa. Sementara sebagai perbandingan Fasilitas Kampung KB yang ada di Kelurahan Pipitan memiliki 1 unit Pos KB yang petugasnya terdiri dari, bidan, PLKB, Kader, tokoh masyarakat, tokoh agama, serta petugas sukarela 
keluarga berencana dan 12 Posyandu dengan 60 Kader Posyandu sedangkan di Kelurahan Nyapah tidak terdapat Pos KB. Hal ini menjadikan pelayan KB yang ada di Kelurahan Nyapah belum maksimal.

Ketiga, belum maksimalnya partisipasi masyarakat dalam pelaksanaan program Kampung KB, salah satu faktor utamanya adalah komunikasi antar organisasi belum berjalan dengan baik antara pokja dan kelompok kegiatan yang ada di Kampung KB.

Partisipasi masyarakat dalam kegiatan pembinaan program kampong $\mathrm{KB}$ belum maksimal, hal ini bisa terlihat dari jumlah keluarga yang mengikuti tidak sesuai dengan target/sasaran kelompok kegiatan pada Desember 2020. Sasaran Bina Keluarga Balita (BKB) sebanyak 131 sesuai dengan sasaran kelompok kegiatan, sementara untuk Bina Keluarga Remaja (BKR) dari sasaran kelompok kegiatan sebanyak 30 yang mengikuti sebanyak 27 kelompok, kemudian untuk Bina Keluarga Lansia dari sasaran kelompok kegiatan sebanyak 25 yang mengikuti sebanyak 20 kelompok. Hal ini menunjukkan belum maksimalnya partisipasi masyarakat yang tergabung dalam Bina Keluarga Remaja dan Bina Keluarga Lansia.

Fokus penelitian ini juga pernah diangkat sebagai topik penelitian oleh beberapa peneliti sebelumnya. Diantaranya sepeti yang dilakukan oleh Nurjannah \&
Susanti (2018), yang menunjukkan bahwa bahwa implementasi program Kampung KB di Kabupaten Kuningan secara umum berjalan dengan baik, hal ini dilihat dari terjadinya peningkatan akseptor KB antara sebelum dan sesudah ditetapkan sebagai Kampung KB yaitu dari 5.244 akseptor menjadi 5.519 akseptor. Kemudian, beberapa kegiatan Program KB sebagian besar telah dilakukan seperti penyuluhan, pembentukan Pusat Informasi dan Konseling Remaja, Bina Keluarga dan UPPKS. Hanya saja dari penelitian kualitatif ditemukan beberapa kendala yang terjadi seperti kurangnya antusias dan pemahaman dari masyarakat dan kurangnya kerjasama antar SDM yang menjalankannya. Kesimpulan dari penelitian ini terdapat peningkatan akseptor $\mathrm{KB}$ antara sebelum dan sesudah ditetapkan sebagai Kampung KB di wilayah Kabupaten Kuningan. Saran kepada Pemerintah Daerah agar membantu dalam merealisasikan wilayah/desa yang belum membentuk Kampung KB.

Ramadhani (2020),dalam penelitian tentang Implementasi Program Kampung Keluarga Berencana di Kelurahan Sidotopo Kecamatan Semampir Kota Surabaya yang menggunakan teori implementasi yang dikemukakan oleh George C. Edward III. Hasil penelitian yang diperoleh yaitu: komunikasi dalam penyelenggaraan Program Kampung KB di Kelurahan 
Sidotopo sudah terimplementasi, sumber daya belum optimal karena kendala dana yang dianggarkan dalam kegiatan sosialisasi untuk konsumsi masyarakat, disposisi terkait sikap pelaksana yang selalu aktif dalam penyuluhan sosialisasi guna untuk meningkatkan ketanggapan respons masyarakat untuk ber-KB, dan faktor struktur birokasi sudah memiliki SOP dan struktur organisasi secara tertulis bagi tim pokja Kampung KB Kelurahan Sidotopo.

\section{METODE}

Penelitian bertujuan untuk mendeskripsikan mengenai pelaksanaan program, mengetahui faktor-faktor yang menghambat pelaksanaan program, dan upaya-upaya yang dapat dilakukan dalam memperbaiki implementasi program Kampung KB dengan menggunakan teori model Donald S.Van Meter dan Carl E. Van Horn (Subarsono, 2005) Data yang dikumpulkan dalam penelitian ini terbagi menjadi dua kelompok, yaitu Data Primer dan Data Skunder.

Penelitian ini adalah penelitian kualitatif dengan tidak menggeneralisasikan jawaban penelitian, maka semua hasil wawancara yang dikemukakan informan dijelaskan secara singkat dengan bentuk kesimpulan dalam pembahasan penelitian dengan menyesuaikan terhadap teori penelitian.
Berdasarkan kategori-kategori yang telah disusun oleh peneliti berdasarkan dengan hasil lapangan yaitu: ukuran dan tujuan kebijakan, sumber daya, karakteristik agen pelaksana, sikap/kecenderungan (disposisi) para pelaksana, komunikasi antar organisasi dan aktivitas pelaksana, dan lingkungan ekonomi, sosial dan politik.

Informan penelitian terdiri dari lima katagori dimanfaatkan oleh peneliti untuk memberikan informasi tentang kondisi yang terjadi (Tabel 2).

Tabel 2 Katagori dan spesifikasi Informan

\begin{tabular}{|c|c|c|}
\hline No. & $\begin{array}{l}\text { Kategori } \\
\text { Informan }\end{array}$ & Spesifikasi Informan \\
\hline 1. & $\begin{array}{l}\text { Dinas } \\
\text { Pemberdayaan } \\
\text { Perempuan, } \\
\text { Perlindungan } \\
\text { Anak, dan } \\
\text { Keluarga } \\
\text { Berencana Kota } \\
\text { Serang }\end{array}$ & $\begin{array}{l}\text { Pelaksana Bidang } \\
\text { Pemberdayaan } \\
\text { Perempuan dan Keluarga }\end{array}$ \\
\hline 2. & $\begin{array}{l}\text { Badan } \\
\text { Kependudukan } \\
\text { dan Keluarga } \\
\text { Berencana } \\
\text { Nasional } \\
(\text { BKKBN) } \\
\end{array}$ & Pelaksana \\
\hline 3. & $\begin{array}{l}\text { Dinas } \\
\text { Kesehatan Kota } \\
\text { Serang }\end{array}$ & $\begin{array}{l}\text { Pelaksana Bidang } \\
\text { Kesehatan Keluarga }\end{array}$ \\
\hline \multirow[t]{3}{*}{4.} & \multirow{3}{*}{$\begin{array}{l}\text { Penyelenggara } \\
\text { Program } \\
\text { Kampung KB } \\
\text { Nyapah }\end{array}$} & $\begin{array}{l}\text { Ketua Pokja Kampung } \\
\text { KB Kelurahan Nyapah }\end{array}$ \\
\hline & & Kepala Seksi SK KKBK \\
\hline & & $\begin{array}{l}\text { Tenaga Kesehatan } \\
\text { Kampung KB Kelurahan } \\
\text { Nyapah }\end{array}$ \\
\hline \multirow[t]{3}{*}{5.} & \multirow[t]{3}{*}{ Masyarakat } & Kader Kampung KB \\
\hline & & Peserta KB \\
\hline & & Bukan Peserta KB \\
\hline
\end{tabular}

Data yang akan dikumpulkan dalam penelitian ini terbagi menjadi dua 
kelompok, yaitu data priemer dan data sekunder.

Untuk memperoleh data yang diperlukan dalam penelitian ini, digunakan metode pengumpulan data melalui wawancara, bbservasi; dokumentasi, dan triangulasi data.

Setelah diadakan penelitian dan pengumpulan data di lapangan, baik melauli wawancara dan observasi partisipatif dengan informan dan setelah melakukan proses reduksi data maka didapatkan data-data yang dibutuhkan dalam penelitian ini dan data-data tersebut akan dijelaskan dalam penelitian ini.

Teknik analisis data yang digunakan pada penelitian ini adalah analisis deskriptif kualitatif. Teknik analisis deskriptif kualitatif adalah untuk menggambarkan suatu fenomena dan ciri-cirinya. Peneliti ingin mengetahui, mengidentifikasi, dan kemudian menggambarkan bagaimana pelaksanaan Program Kampung KB di Kelurahan Nyapah Kecamatan Walantaka Kota Serang.

\section{HASIL DAN PEMBAHASAN}

Program Kampung KB adalah sebuah kebijakan publik Dengan kata lain kebijakan publik merupakan suatu program pencapaian tujuan, nilai-nilai dan praktikpraktik yang terarah (Islamy, 2012). Keterarahan tujuan dan nilai tersebut diukur dengan indikator-indikator yang disepakati pembuat kebijakan. Dalam pedoman Pengelolaan Kampung KB (BKKBN, 2017) dinyatakan bahwa indikator keberhasilan program Kampung KB adalah sebagai berikut:

Indikator Input; yaitu: 1) Tingginya Partisipasi seluruh potensi Kampung untuk kemajuan Kampung KB; 2) Beragamnya kegiatan yang dilaksanakan secara terpadu baik program pemerintah maupun inovasi masyarakat; 3) Besarnya sumber anggaran Kampung KB yang didapat baik dari iuran masyarakat, bantuan pemerintah maupun donator yang tidak mengikat; 4) Ketersediaan sarana dan prasarana.

Indikator Proses: 1) Berjalannya kegiatan dimasing-masing seksi; 2) Peran serta petugas Pemerintah dalam sinkronisasi kegiatan; 3) Peran serta institusi masyarakat dalam pengelolaan Kampung KB; 4) Menjalankan 8 (delapan) fungsi keluarga dilaksanakan disetiap keluarga; 5) Frekuensi dan kualitas kegiatan KIE/Penyuluhan; 6) Frekuensi pelayanan KB-KR; 7) Frekuensi pelayanan dari sektor lainnya; 8) Frekuensi pertemuan berkala kelompok-kelompok kegiatan (baik program Kependudukan Keluarga Berencana dan Pembangunan Keluargamaupun kegiatan sektor terkait di Kampung KB); 9) Frekuensi kegiatan gerakan masyarakat Kampung KB. 
Indikator Output: Keberhasilan kampung KB dapat diukur dari pelaksanaan 8 fungsi di masing-masing keluarga yaitu: 1) Meningkatnya pelaksanaan keagamaan (Keluarga semakin rajin beribadah); 2) Meningkatnya pengetahuan dan keterampilan masyarakat baik ilmu pengetahuan maupun profesionalisme (semakin banyak orang yang memiliki keterampilan untuk meningkatkan usaha); 3) Tercapainya rata-rata dua anak setiap keluarga, keluarga sehat, anak tumbuh dan berkembang dengan baik; 4) Meningkatnya income per kapita keluarga dan pemanfaatannya menunjang kepentingan keluarga; 5) Terlindunginya masyarakat/keluarga dan hidup tentram dan nyaman; 6) Semakin terjalinnya hubungan harmonis antar anggota keluarga dan antara keluarga dengan masyarakat dan lingkungan; 7) Semakin berkembangnya budi pekerti, tata krama dan seni budaya baik di keluarga maupun masyarakat sekampung; 8) Semakin tertatanya lingkungan yang serasi selaras dan seimbang antara perilaku dan lingkungan

Untuk memperoleh pemahaman yang mendalam apakah pelaksanaan Program Kampung KB di Kelurahan Nyapah Kecamatan Walantaka sudah berjalan dengan baik, maka setiap indikator yang telah disebutkan dapat dirasakan dan dilihat dalam bentuk nyata berupa kegiatankegiatan lapangan oleh para pelaksana.
Berikut analisis pelaksanaan Program Kampung KB di Kelurahan Nyapah Kecamatan Walantaka Kota Serang.

\section{Ukuran dan Tujuan Kebijakan}

Untuk melihat pelaksanaan program Kampung KB di Kelurahan Nyapah Kecamatan Walantaka Kota Serang, dengan ini mendasarkan pada tujuan kebijakan Peraturan Daerah Kota Serang Nomor 7 Tahun 2019 tentang Perkembangan Kependudukan dan Pembangunan Keluarga, Keluarga Berencana, serta Sistem Informasi Keluarga. Hal ini tentunya dapat berdampak positif terhadap pelaksanaan program Kampung KB.

Tujuan yang ada pada program Kampung KB di Kelurahan Nyapah, diharapkan sudah sesuai dengan keinginan masyarakat, karena setiap kebijakan pemerintah selalu menyasar masyarakat akar rumput yang berada pada titik terbawah yang menerima kebijakan tersebut. Manfaat yang paling besar yang dirasakan dengan adanya program Kampung KB ini adalah, lingkungan Kampung KB yang mendapatkan perhatian dari berbagai pihak, baik pemerintah maupun nonpemerintah

Dari hasil wawancara yang mendalam dengan beberapa informan penelitian dapat ditarik kesimpulan bahwa pelaksanaan Program Kampung KB di Keluraha Nyapah sudah tepat sasaran, dan 
sudah tepat sekali di laksanakan di Kelurahan Nyapah Kecamatan Walantaka karena masyarakat setempat menilai bahwa Program KB bisa menekan laju pertumbuhan penduduk di wilayah mereka, sehingga bisa menekan angka kelahiran dari tahun ke tahun.

\section{Sumber Daya}

Sumber daya dijabarkan dengan 3 (empat) sub aspek yaitu Sumber Daya Manusia (SDM), waktu, pembiayaan, dan sarana dan prasarana. Sub aspek ini ditetapkan sebagai daya dukung utama dalam pelaksanaan kebijakan karena sumber daya merupakan bagian penting dalam menjamin keberhasilan suatu kebijakan, sumber daya yang baik dan cukup akan berdampak pada pelaksanaan kebijakan yang baik dan terarah serta tercapainya suatu tujuan kebijakan dan memberi manfaat kepada masyarakat. Aspek ini digunakan untuk melihat apakah sumber daya yang ada cukup, layak, dan memadai dalam memberikan akses layanan kepada peserta yang termasuk kedalam anggota kelompok KB.

\section{Sumber Daya Manusia}

Berhasil atau tidak sebuah program tidak lepas dari Sumber daya manusia karena manusia merupakan salah satu sumber daya yang yang bisa membantu keberhasilan proses pelaksanaan program
KB, karena pada dasarnya sumber daya manusia adalah motor penggerak dari pelaksanaan kebijakan. Untuk Sumber Daya Manusia yang membantu pelaksanaan Program Kampung KB di Kelurahan Nyapah Kecamatan Walantaka yaitu PLKB Kecamatan Walantaka, Penyelenggara Program Kampung KB dan Kader

Dalam pelaksanaan program Kampung KB PLKB dan kader sudah dibekali materi-materi dasar tentang $\mathrm{KB}$ serta sosialisasi mengenai program KB oleh DP3AKB Kota Serang. Dalam pemilihan PLKB, DP3AKB telah memilih para petugas yang mumpuni dan menguasai dan bahkan sudah memahami apa yang akan disampaikan dalam program KB. Para petugas mendapakan pelatihan dasar umum atau LDU yang mencakup seluruh bidang program KKBPK baik program konseling, manajemen, kependudukan dan lainnya Hal ini juga tidak jauh berbeda dari hasil hasil wawancara penulis dari informan penelitian.

\section{Sumber Daya Finansial}

Menurut Pedoman Pengelolaan Kampung KB (2017) Sumber-sumber pembiayaan kampung $\mathrm{KB}$ adalah 1) Iuran warga Kampung KB; 2) APBDesa/Kelurahan; 3) APBD II; 4) APBN; 5) Alokasi Dana Desa; 6) Dana Desa; 7) Kemitraan/CSR (corporation 
social responsibility) yaitu iuran atau kepedulian perusahaan untuk pembangunan); dan 8) Sumber-sumber lain yang tidak mengikat.

Dana dan anggaran dalam menunjang program kampung $\mathrm{KB}$ ada dari BKKBN melalui DAK (Dana Alokasi Khusus) BOKB (Bantuan Operasional Keluarga Berencana) untuk kabupaten/kota, itu kurang lebih untuk daerah DTPK itu 105 juta pertahun, non DTPK itu 100 juta pertahun (daerah tertinggal, perbatasan dan kepulauan terluar). Sedangkan menurut DP3AKB DAK (dana alokasi khusus) itu bukan khusus untuk kampung KB saja, tapi untuk pelayanan KB juga.

Minimnya dana yang dapat digunakan untuk menyediakan fasilitas yang cukup baik untuk kampung KB di Kelurahan Nyapah juga disebabkan kurangnya perhatian dari pemerintah daerah untuk memenuhi ketersediaan fasilitas kampung KB. Yang tidak bisa diabaikan juga adalah menurunnya kapasitas keuangan daerah khususnya APBD Kota Serang akibat dampak pandemic Covid-19, hal ini juga berdampak kepada ketersediaan anggaran yang cukup untuk pemenuhan fasilitas pelayanan $\mathrm{KB}$ dilapangan.

\section{Sumber Daya Waktu}

Penyuluhan sering dilakukan di balai desa yang biasanya dilakukan satu bulan sekali oleh PLKB untuk memberikan arahan maupun pemahaman mengenai $\mathrm{KB}$ kepada masyarakat agar dapat lebih memahami tujuan dari program $\mathrm{KB}$ itu sendiri. Orang-orang yang terlibat dalam kegiatan adalah tenaga pendamping penyuluhan.

\section{Karakteristik Agen Pelaksana}

DP3AKB adalah lembaga daerah yang sudah dibawah gubernur, sedangkan BKKBN adalah instansi vertikal yang langsung dibawah BKKBN pusat. Karena ini amanat undang-undang nomor 23 tahun 2014, ada pembagian kewenangan pelaksanaan program KKBPK antara pusat dan daerah. BKKBN di provinsi tidak melaksanakan fungsi provinsi, tetapi melaksanakan fungsi kewenangan BKKBN pusat yang ada didaerah. Program KB inisiasinya ada di BKKBN. DP3AKB berperan berdasarkan pasal 2 peraturan walikota nomor 14 tahun 2017, tugas pokok melaksanakan urusan wajib non pelayanan dasar di bidang pemberdayaan perempuan, perlindungan anak dan pelayanan program keluarga berencana. Fungsinya untuk perumusan, pelaksanaan, evaluasi dan administrasi urusan dibidang pemberdayaan perempuan dan masyarakat, perlindungan perempuan dan anak, pengendalian penduduk, advokasi penggerakan dan informasi serta keluarga berencana, ketahanan dan kesejahteraan 
keluarga. Dapat disimpulkan, karakteristik agen pelaksana pada pelaksanaan program kampung $\mathrm{KB}$ dalam hal ini $\mathrm{BKKBN}$ bersifat fleksibel karena BKKBN dapat turun kelapangan langsung apabila ada kepentingan seperti melakukan monitoring dan evaluasi kampung KB, juga melakukan pembinaan langsung ke kampung $\mathrm{KB}$. BKKBN tetap berada dalam posisi teratas membawahi pihak pelaksana kampung KB seperti DP3AKB, UPT Kecamatan Walantaka dan pokja kampung KB. Pihak pelaksana melaksanakan tugasnya sesuai dengan wewenangnya masing-masing.

\section{Sikap/Kecenderungan (Disposisi) Para Pelaksana}

Disposisi atau sikap para pelaksana merupakan faktor salah satu hal penting dalam pendekatan pelaksanaan sebuah kebijakan publik. Disposisi ini merupakan kemauan, keinginan, dan kecenderungan sikap pelaksana untuk melaksanakan dengan sungguh-sungguh agar apa yang menjadi tujuan bisa terwujud (Widodo, 2010). Keberhasilan dari kebijakan dapat dilihat dari disposisi (karakteristik agen pelaksana). Dalam masalah, itu yang akan ditinjau adalah penugasan pegawai/pejabat yang berorientasi pada sikap dan keseriusan.

Sehubungan dengan penelitian ini, pelaksanaan Program Kampung KB mendapatkan respon yang positif dari para pelaksana yaitu DP3AKB Kota Serang khususnya bidang Keluarga Berencana dan Keluarga Sejahtera dan Sub Bidang KB. Peran pemerintah Daerah Kota Serang dalam mendukung program Kampung KB bisa terlihat dari beberapa hal yaitu 1) monitoring dan evaluasi program; 2) menggerakkan Pogram Kampung KB dari Kota Ke Kecamatan dalam rangka meningkatkan pemahaman dan kesadaran keluarga dan masyarakat terhadap program $\mathrm{KB}$ dan meningkatkan kemampuan para pengelola KKBPK di tingkat Kecamatan dalam penggerakan program KKBPK di lapangan; 3) menggerakkan Pogram Kampung KB dari Kecamatan $\mathrm{Ke}$ Kelurahan dalam rangka meningkatkan pemahaman keluarga dan masyarakat terhadap program KB melalui kegiatan KIE oleh Tim Operasional KKBPK tingkat Kecamatan dan melakukan pembinaan dan fasilitasi terhadap petugas lapangan, mitra kerja dalam pengelolaan program KB lini lapangan;

\section{Komunikasi Antarorganisasi dan Aktivitas Pelaksana}

Indikator selanjutnya yang mempengaruhi keberhasilan pelaksanaan suatu kebijakan, menurut Van Meter dan Van Horn, adalah komunikasi. Komunikasi yang terjalin selama ini antara pemerintah daerah, aparatur pelaksana dan kelompok 
kerja terkait pelaksanaan program Kampung KB di Kelurahan Nyapah Kecamatan Walantaka dilakukan melalui pembinaan-pembinaan langsung dan sudah berjalan dengan baik.

Partisipasi berbagai instansi dalam kampung $\mathrm{KB}$ sangat penting sehingga pelayanan paripurna dapat dirasakan langsung oleh masyarakat menuju kesejahteraan rakyat. Kampung KB berupaya memberdayakan dan memberikan kemudahan kepada masyarakat untuk memperoleh pelayanan total program KB sebagai upaya mewujudkan keluarga sejahtera yang berkualitas (Mardiyono, 2017).

Koordinasi yang dilakukan oleh pemerintah, aparatur pelaksana dan kelompok kerja terkait teknis pelaksanaan program Kampung KB di Kelurahan Nyapah dilakukan dengan penyuluhan dan pertemuan-pertemuan formal dan informal seperti rapat dan monitoring langsung ke lapangan agar terjalin komunikasi yang baik antara pemerintah daerah dan pelaksana Program Kampung KB .

Dalam praktik pelaksanaan program $\mathrm{KB}$, Bentuk koordinasi dilakukan secara bertahap. Pertama dalam proses persiapan pelaksanaan program KB. DP3AKB Kota Serang sebagai penanggungjawab utama para agen pelaksana program KB mengutus PLKB di tiap kecamatan. PLKB tersebut sudah diberi bekal mengenai bagaimana pelaksanaan program KB yang harus dilaksanakannya di tingkat kecamatan.

\section{Lingkungan Ekonomi, Sosial dan Politik}

Hal terakhir yang perlu juga diperhatikan guna menilai kinerja pelaksanaan publik dalam sudut pandang yang ditawarkan oleh Van Meter dan Van Horn adalah sejauh mana lingkungan eksternal turut yang turut memajukan keberhasilan kebijakan publik yang telah ditetapkan. Lingkungan yang dimaksud termasuk lingkungan sosial, ekonomi dan politik. Dan lingkungan yang tidak harmonis dan kondusif dapat menjadi dalang dari kegagalan kinerja pelaksanaan kebijakan. Oleh sebab itu, upaya untuk pelaksanaan kebijakan harus pula memperhatikan kekondusifan kondisi lingkungan eksternal.

Secara ekonomi dan sosial, masyarakat masyarakat belum sepenuhnya berpatisipasi pada program Kampung KB, masyarakat kurang memahami atau kurang mempunyai kesadaran akan pentingnya KB. Beberapa faktor menjadi penyebab rendahnya antusiasme warga, seperti rendahnya tingkat pendidikan mereka, terlalu fanatik terhadap agama yang dianut, dan lain sebagainya

Kondisi ekonomi yang terjadi saat pelaksanaan Program Kampung KB adalah kemiskinan pada warga sekitar Kelurahan Nyapah Kecamatan Walantaka. Keadaan ini yang menjadikan program KB kurang 
mendapatkan respon yang bagus. Warga terlalu memikirkan biaya yang harus ditanggung saat pemasangan KB. Warga juga lebih memprioritaskan kebutuhan hidup sehari-hari daripada digunakan untuk ber-KB. DP3AKB, dan Pemerintah Kota Serang sudah memikirkan apa yang dikhawatirkan warga. Mereka juga sudah membuat solusinya dengan menggratiskan apabila ada yang ingin mendaftar. Hanya saja mungkin kesadaran warga mengenai KB yang kurang. Selain hal itu, juga karena kurangnya kesadaran masyarakat yang termasuk kedalam Pasangan Usia Subur (PUS) yang belum mengikuti sebagai peserta Keluarga Berencana (KB)(Tabl 3).

Tabel 3 Pasangan Usia Subur (PUS) bukan Peserta KB (Desember 2020)

\begin{tabular}{|c|l|c|}
\hline No. & \multicolumn{1}{|c|}{ Jenis KB } & Jumlah \\
\hline 1. & Hamil (H) & 61 \\
\hline 2. & Ingin Anak Segera (IAS) & 18 \\
\hline 3. & Ingin Anak Ditunda (IAT) & 24 \\
\hline 4. & $\begin{array}{l}\text { Tidak Ingin Anak Lagi } \\
\text { (TIAL) }\end{array}$ & 38 \\
\hline & $\begin{array}{l}\text { Jumlah PUS Bukan Pesera } \\
\text { KB }\end{array}$ & 141 \\
\hline
\end{tabular}

Sumber: Laporan Bulanan Pengendalian Lapangan Tingkat Kelurahan Sistem Informasi Kependudukan dan Keluarga, Kelurahan Nyapah

Berdasarkan Tabel 3 diketahui bahwa jumlah pasangan usia subur yang bukan peserta KB di Kelurahan Nyapah sebanyak 141 orang, dengan rincian pasangan usia subur yang Hamil (H) sebanyak 61 orang, Ingin Anak Segera (IAS) sebanyak 18 orang, Ingin Anak Ditunda (IAT) sebanyak 24 orang, dan Tidak Ingin Anak Lagi (TIAL) sebanyak 38 orang. Sementara itu sebagai perbandingan Kampung KB di Kelurahan Pipitan yang terdapat 1.268 Pasangan Usia Subur (PUS) yang terdaftar melakukan KB sedangkan sebanyak 199 Pasangan Usia Subur (PUS) yang tidak melakukan KB

Dari enam indikator tentang keberhasilan pelaksanaan suatu kebijakan publik menurut Donalds S. Van Meter dan Van Horn bisa disimpulkan beberapa faktor yang menghambat implementasi program Kampung KB di Kelurahan Nyapah diantaranya adalah; 1) minimnya sumber daya finansial yang ada, ini juga menyebabkan kurangnya fasiitas kesehatan yang mendukung pelaksanaan program kampung KB; 2) Kurangnya kesadaran masyarakat yang termasuk kedalam Pasangan Usia Subur (PUS) yang belum mengikuti sebagai peserta Keluarga KB; 3) kurangnya partisipasi dan kesadaran Masyarakat dalam Pembinaan Ketahanan Keluarga di program Kampung KB Kelurahan Nyapah.

Adapun upaya untuk memperbaiki pelaksaan program kampung $\mathrm{KB}$ di Kelurahan Nyapah Kecamatan Walantaka Kota Serang adalah dengan: 1) melakukan evaluasi program; 2) evaluasi ketersediaan sumber daya yang mendukung; dan 3) 
melakukan koordinasi secara vertikal dan horizontal.

\section{KESIMPULAN DAN REKOMENDASI}

\section{Kesimpulan}

Hasil penelitian menunjukkan bahwa pelaksanaan Program Kampung KB dikelurahan Nyapah belum berjalan dengan maksimal hal ini dilihat dari pelaksanaan program ini yang tidak berjalan dengan baik karena ada beberapa hambatanhambatan diantaranya adalah sumber daya finansial; partisipasi dan kesadaran masyarakat dalam pembinaan ketahanan keluarga di program kampung KB Kelurahan Nyapah, kurangnya kesadaran masyarakat yang termasuk kedalam Pasangan Usia Subur (PUS) yang belum mengikuti sebagai peserta KB. Adapun upaya untuk memperbaiki pelaksaan program kampung $\mathrm{KB}$ di Kelurahan Nyapah Kecamatan Walantaka Kota Serang adalah dengan melakukan evaluasi program; evaluasi ketersediaan sumber daya yang mendukung dan melakukan koordinasi secara vertikal dan horizontal

\section{Rekomendasi}

Berdasarkan kesimpulan dari hasil penelitan yang telah dilakukan, maka saran peneliti adalah sebagai berikut :

1. BKKBN dan DP3AKB melakukan inventerisasi terhadap kebutuhan sarana dan prasarana di Kampung KB dengan memaksimalkan anggaran yang ada untuk memajukan kampung KB.

2. DP3AKB terus melaksanakan monitoring terhadap pokja $\mathrm{KB}$ dan pelaksana kegiatan di kampung $\mathrm{KB}$, serta melakukan pembinaan berkelanjutan untuk memberikan pengertian dan terhadap pengelolaan kampung KB.

3. Pelaksana kampung KB lebih intens lagi menyampaikan program kampung KB serta penyuluhan dan sosialisasi kepada masyarakat mengenai kampung KB.

4. Masyarakat serta pokja KB harus pro aktif untuk bekerjasama dengan berbagai pihak yang dibutuhkan di Kelurahan Nyapah untuk program KB.

\section{DAFTAR PUSTAKA}

Agustino, L. (2006). Dasar-dasar kebijakan Publik. Bandung: Alfabeta

BPS Kota Serang, (2020). Kota Serang Dalam Angka. BPS-RI. Indonesia (diolah)

BPS RI. (2021). Berita Resmi Statistik Nomor 07/01/Th. XXIV.21 januari 2021 ,

Islamy, M. I. (2012). Kebijakan Publik, Tangerang Selatan: Universitas Terbuka.

Kemenkominfo, (2016). Kampung KB: Inovasi Strategis Memberdayakan Masyarakat.

https://kominfo.go.id/index.php/cont ent/detail/9841/kampung-kb-inovasistrategis-memberdayakanmasyarakat/0/artikel_gpr 
Mardiyono. (2017). Pemberdayaan Keluarga Melalui Kampung KB Dalam Upaya Peningkatan Program KKBPK dan Terkait di Jawa Timur. Jurnal Keluarga Berencana, 2(1): 110.

Nurjannah, S. N. \& Susanti, E. (2018). Implementasi Program Kampung Keluarga Berencana KB Di Kabupaten Kuningan Tahun 2018 (Studi Kuantitatif Dan Kualitatif). Jurnal Ilmu Kesehatan Bhakti Husada: Health Sciences Journal, 09(02): .

Ramadhani N, T. (2020). Implementasi Progr, am Kampung Keluarga Berencana Di Kelurahan Sidotopo Kecamatan Semampir Kota Surabaya, Public Administration Journal of Research, 2 (4): 376-3 92.

Singarimbun, M. 1996. Penduduk dan Perubahan. Yogyakarta: Pustaka Pelajar Offset.

Widodo, J. (2010). Analisa Kebijakan Publik. Malang: Bayu Media.

Peraturan Walikota Serang Nomor 14 tahun 2017 tntang Kedudukan, Susunan Organisasi, Tugas Dan Fungsi Serta Tata Kerja Dinas Pemberdayaan Perempuan, Perlindungan Anak Dan Keluarga Berencana

Subarsono,A.G. (2005). Analisis Kebijakan Publik: Konsep, Teori dan Aplikasi. Yogyakarta :Pustaka Pelajar. 